\title{
Photoreactivity of Oil and Alcoholic Diterpenic Varnishes: Key Role of the Polymerization Process
}

\author{
Dr. Clara Azemard ${ }^{[a] \mathscr{H}}$, Dr.Matthieu Ménager ${ }^{[\mathrm{a}] * \mathscr{H}}$, Prof. Mohamed Sarakha ${ }^{[b]}$, Prof. Cathy
} Vieillescazes $^{[\mathrm{a}]}$

a IMBE UMR, Avignon University/CNRS/IRD/AMU, Restoration Engineering of Natural and Cultural Heritage, Faculty of Sciences, Avignon, France.

${ }^{b 2}$ CNRS, SIGMA Clermont, Clermont-Ferrand Institute of Chemistry, Clermont Auvergne University, F63000, Clermont-Ferrand, France

*Correspondance to: Dr. Matthieu Ménager - Restoration Engineering of Natural and Cultural Heritage- IMBE, Avignon university- UFR-ip STS, Campus Jean-Henri Fabre - 301 rue Baruch de Spinoza BP 21239, 84916 Avignon Cedex 9 , France.

E-mail: matthieu.menager@univ-avignon.fr.

${ }^{\mathscr{H}}$ Dr. Clara Azemard and Dr. Matthieu Ménager contributed equally to this work. 


\section{$\underline{\text { Abstract }}$}

The conservation of artworks is a key issue in cultural heritage. The alterations of the varnish could be linked mainly to the photopolymerization of the natural resin. The photodegradation of sandarac and rosin under simulated solar light was studied using a multianalytical approach using a second derivative FT-IR spectroscopy and gas chromatography coupled to mass spectroscopy.

In all resins, main terpene molecules underwent esterification and perestererifications via the formation of hydroperoxides preferentially formed on tertiary carbons. This polymerization could be associated with the advice of important art manuals and treatises recommending exposing varnishes to the sunlight while drying. In a second step, these esters and perester bonds underwent photoscissions by Norrish I and II reactions, leading to the production of free terpenes in the varnishes. In sandarac varnishes, the vinyl bonds showed a strong reactivity associated with the formation of trans and cis secondary alkenes. These photochemical reactions could explain an important part of the problem of conservation of the varnish layers experienced by museums all over the world. 


\section{Introduction}

The conservation of artworks is a key issue in cultural heritage. In many cases, varnishes have a primordial function in the preservation and the visual improvement of the aesthetic layer, like the pictorial layer, of paintings. They are considered as a constitutive part of the artwork as they participate to it by their color or their thickness which can give depth. ${ }^{[1]}$ Since the $12^{\text {th }}$ century at least, artists have been trying to find the "perfect" varnish and many recipes and advice can be found in manuscripts and books from middle age to nowadays. ${ }^{[2-16]}$ In particular, the VERNIX database created by the Cité de la musique in Paris, ${ }^{[17]}$ already made an inventory of more than 250 varnishes from the $14^{\text {th }}$ to the $18^{\text {th }}$ centuries.

Varnishes are constantly exposed to light and undergo photochemical reactions altering their physicochemical properties. Moreover, they are the principal material in contact with the environment and therefore can react with its oxidative chemical species. The alteration of varnishes has important consequences on the visual aspect of the artworks. Yellowing, crackling, chanci, blueing, or clogging are some of the effects encountered on this protective layer after ageing. ${ }^{[18]}$ Among all possible causes, photodegradation is one of the most important possible causes of alteration among pollutants, ${ }^{[19-22]}$ biodegradation, ${ }^{[23,24]}$ and temperature. ${ }^{[20]}$

Therefore, the understanding of the chemical processes and the associated kinetic evolution is primordial to predict the behavior of the varnishes. It enables to make preservation campaign as it was carried out in several museums (change of lamps, protection of the artworks, etc.). In the literature, we can distinguish two different objectives that are to: (i) describe the natural degradation of the material, or/and (ii) understand the mechanisms of degradation. To be able to understand the mechanism in such complex media, it can be useful to simplify (solvent, phase, irradiation wavelengths, etc.) the physicochemical system. As photochemical reactions are extremely dependent on the chemical environment, ${ }^{[25,26]}$ such changes or simplifications always have to be taken into account in the extrapolation of model conditions to the natural conditions. In this publication, we will use the term natural degradation for the studies describing the global degradation of varnishes without differentiating thermic or photochemical reactions.

Natural varnishes are complex chemical matrixes based on natural resins diluted in a medium (alcohol, oil or turpentine spirit for example). ${ }^{[27]}$ Techniques used to prepare such layer are complex and extremely different over human history, ${ }^{[3,7,15,28,29]}$ which sometimes resulted in the loss of their secrets of fabrication. ${ }^{[30-32]}$ Natural resins are constituted of terpenes and ${ }^{[33]}$ as most biomaterials, they vary in their chemical composition in function of taxonomic, ${ }^{[34-37]}$ ecological and conservation parameters. ${ }^{[35]}$ This problem of chemical reproducibility makes the understanding of key photochemical reactions a critical objective to be able to understand the chemical and physical parameters driving the degradation patterns of the varnishes. In this work, we focused on two diterpenic resins: Tetraclinis articulata resin (sandarac) and Pinus resins (the different turpentines and the distillation product colophony or rosin).

Diterpenic resins are mostly composed of diterpenoids, mostly pimaranes, abietanes and labdanes (cf Figure 1). Rosin and turpentine resins are produced by conifers from the Pinaceae family. They are composed of abietanes (abietic, neoabietic, palustric, dehydroabietic (DHA) acids and various hydroxylated derivatives of DHA), pimaranes (pimaric, sandaracopimaric and isopimaric acids) and sometimes labdanes (larixol) in different proportions. ${ }^{[34,38,39]}$

The sandarac resin chemical composition consists in a polymeric fraction and free diterpernoids. The polymeric fraction was identified as polycommunic acid. ${ }^{[21,40]}$ The low molecular weight fraction is generally composed of sandaracopimaric, hydroxy-sandaracopimaric, isopimaric, (iso)agathic, dihydroagathic, dihydroagathalic, pinifolic, and cis- and trans-communic acids, and phenols (manool, totarol, sugiol and ferruginol). ${ }^{[21,30,39,41,42]}$ 


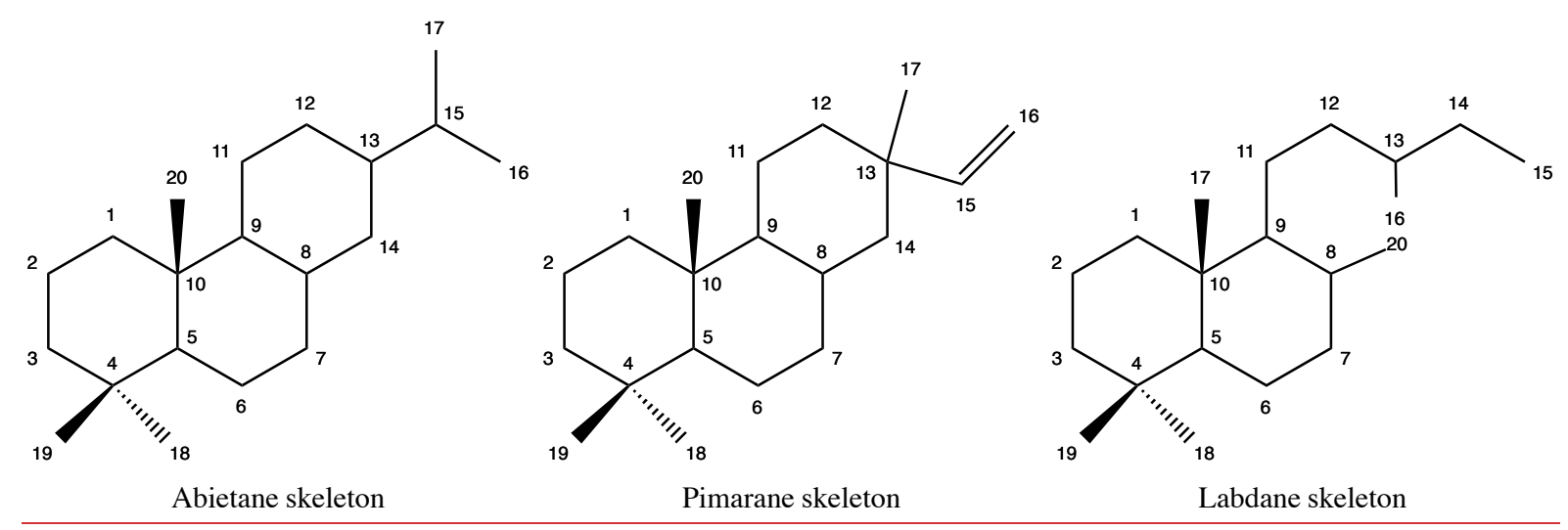

Figure 1 - Structures of the main diterpenes present in rosin and sandarac resins.

The photodegradation of alcoholic varnishes of Pinus resin was studied upon different irradiation devices (Suntest, ${ }^{[38,43]}$ with $\lambda_{\text {exc }}>295 \mathrm{~nm}$ Solar Box,${ }^{[44]}$ with $\lambda_{\text {exc }}>290 \mathrm{~nm}$, fluorescence tubes ${ }^{[45]}$ with $\lambda_{\text {exc }}>330$ $\mathrm{nm}$ and $\lambda_{\text {exc }}>390 \mathrm{~nm}$, UV light, ${ }^{[46]}$ at $\lambda_{\text {exc }}=365 \mathrm{~nm}$ ). Pure Pinus resins were generally reported as undergoing photochemical polymerization, oxidation and dehydrogenation which undergo the formation of aromatic, hydroxy- and oxo- compounds. Most authors described the natural degradation or the photodegradation of abietane, pimarane and labdane compounds of rosin and Venice turpentine alcoholic varnishes into hydroxylated and ketonic compounds, with a large formation of dehydroabietic acid (DHA) and a formation of unknown high molecular weight molecules. ${ }^{[38,40,47,48]}$ Nevertheless, the importance and the mechanism of the polymerization process remain unclear and need further studies as it could be a key to understanding varnish behavior. Oil varnishes were shown to induce the formation of conjugated and non-conjugated hydroperoxides and cross-linking. ${ }^{[46]}$ For the sandarac, Kononenko and co-authors nicely showed the importance of the polymerization of the communic acid in the photoreactivity of the sandarac resin. ${ }^{[32]}$ Cross-linking, cleavage reactions were also mentioned by Scalarone and co-authors. ${ }^{[21]}$ Until now, no study took into account the influence of the formulation of varnishes (oil, alcoholic) on the photochemical mechanisms.

In this article, the photodegradation of the extractable fraction of diterpenic varnishes is studied by infrared (FT-IR) and gas chromatography coupled to mass spectrometry (GC-MS). The three main goals of this paper are (i) to identify the principal photodegradation mechanism taking place in varnishes, (ii) to assess, for the first time, the effect of the formulation on the photochemical reactions, (iii) to understand the formation of polymeric network in the varnishes. Thus, the specificity of the reactions toward the family of compound and the type of varnish was also elucidated using a multianalytical approach on a mechanistic and kinetic point of view. In order to describe the chemical photodegradation of varnish compounds, we used a second derivative and fine smoothing of infrared spectra, which allow a fast deconvolution of the infrared signal. It was combined with gas chromatography coupled to mass spectrometry (GC-MS and GCMS/MS) analysis of the extractable fraction to study the reproducible kinetics. 


\section{$2 \quad$ Results \& discussion}

\section{$2.1 \quad$ Photodegradation of rosin and rosin varnishes}
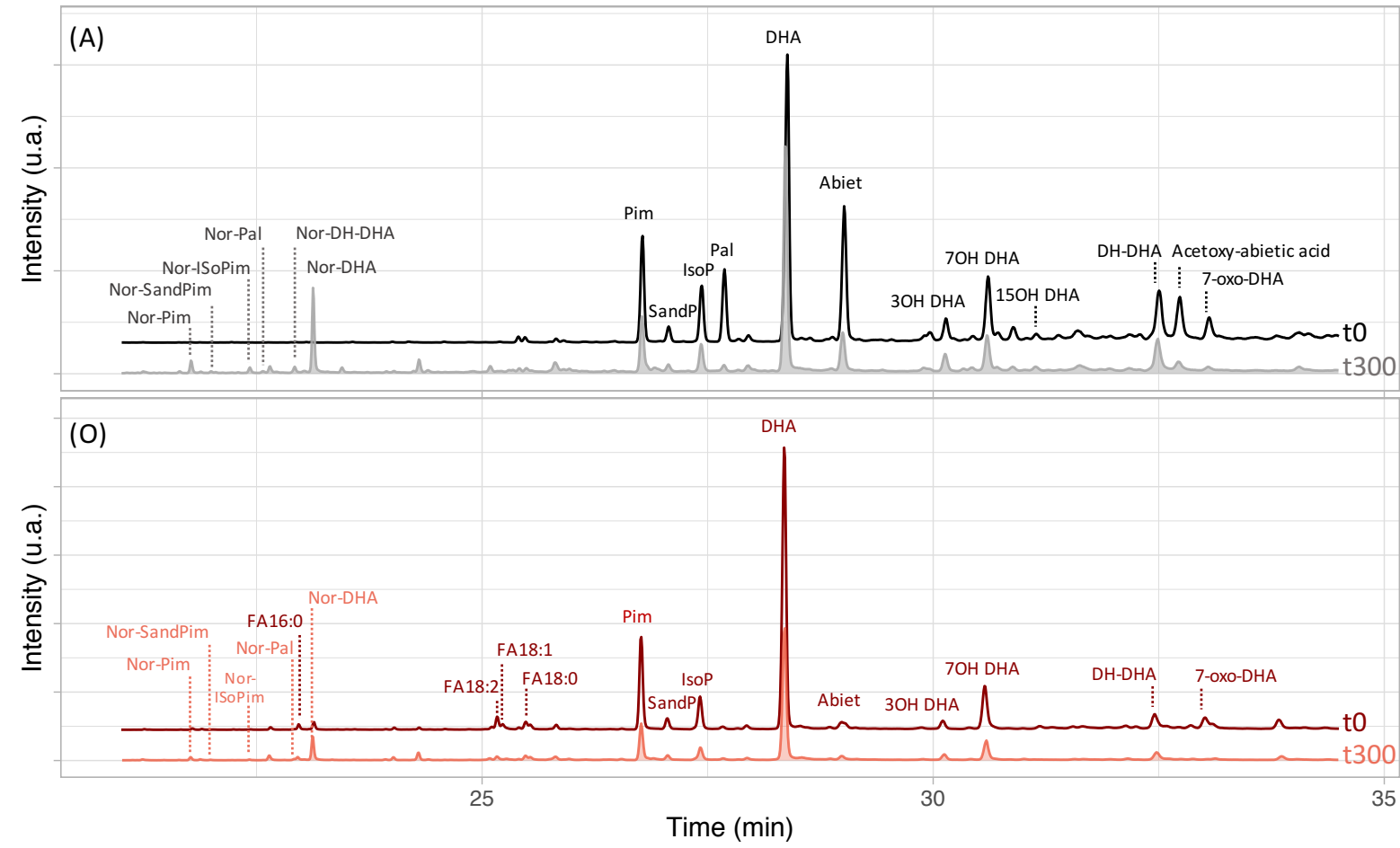

Figure 2 - GC-MS chromatograms of oil (O) and alcoholic(A) varnishes with 0 and 300h of irradiation in Suntest (765 W.m², $35^{\circ} \mathrm{C}$ ). Identified compounds: $\mathrm{Pim}=$ Pimaric acid, SandP $=$ Sandaracopimaric acid, IsoP= Isopimaric acid, Pal $=$ Palustric acid, $\mathrm{DHA}=$ Dehydroabietic acid, Abiet= Abietic acid, 3OH DHA=3-hydroxy-DHA, 7OH DHA=7-hydroxy-DHA, 15OH DHA=15hydroxy-DHA, DH-DHA= Dehydro-DHA, Acetoxy-abietic acid, 7-oxo-DHA, Nor- $=18$-nor-terpene $(\mathrm{H}$ replaces the C18 group), FA18:0 = palmitic acid, FA18:1 = oleic acid, FA18:2 = linoleic acid, FA18:0= stearic acid.

The photodegradation of turpentine resin and rosin at $35^{\circ} \mathrm{C}$ and under simulated solar light was studied. In all experiments, they showed a very similar photochemical behavior, in accordance with literature. ${ }^{[38,43,47]}$ In this publication, we will thus present the results for rosin photodegradation only but the conclusions can be extended to both materials.

First, all observed reactions were photochemically induced and followed by infrared spectrometry and GCMS analyses of the extractable fraction. Indeed, no significant change in the chemical compositions of varnishes change was noticed after 1 month in the dark at ambient temperature $\left(20-25^{\circ} \mathrm{C}\right)$ or in an oven at $40^{\circ} \mathrm{C}$ (data not shown).

GC-MS chromatograms of all fresh rosin varnishes were principally composed of pimaranes and abietanes, most particularly (iso)pimaric, sandaracopimaric, palustric, abietic, dehydroabietic acids (DHA), several hydroxy-DHA, 7-oxo-DHA and dehydro-DHA. The chromatograms of fresh and photodegraded varnishes are given in Figure 2. The identifications were made thanks to the literature and to an advanced study of the MS and MS/MS fragmentation, as already presented in our previous publication. ${ }^{[4]}$

In all varnishes, the irradiation provokes important evolutions of infrared spectra and extractable fraction chromatograms. Many observed kinetics (evolution of different infrared bands, terpenes and other derivatives concentrations) showed a 2-step process that can be described as follows: (i) phase 1 in the first 100 hours, (ii) phase 2 from 100 to 300 hours. In order to understand the chemical process, we studied independently the photoreactivities of the different chemical groups and discussed the GC-MS data all along the text. All infrared bands attribution were made according to the literature. ${ }^{[43,47,48,50-53]}$ 


\subsubsection{Photoreactivity of rosin alcoholic varnishes}
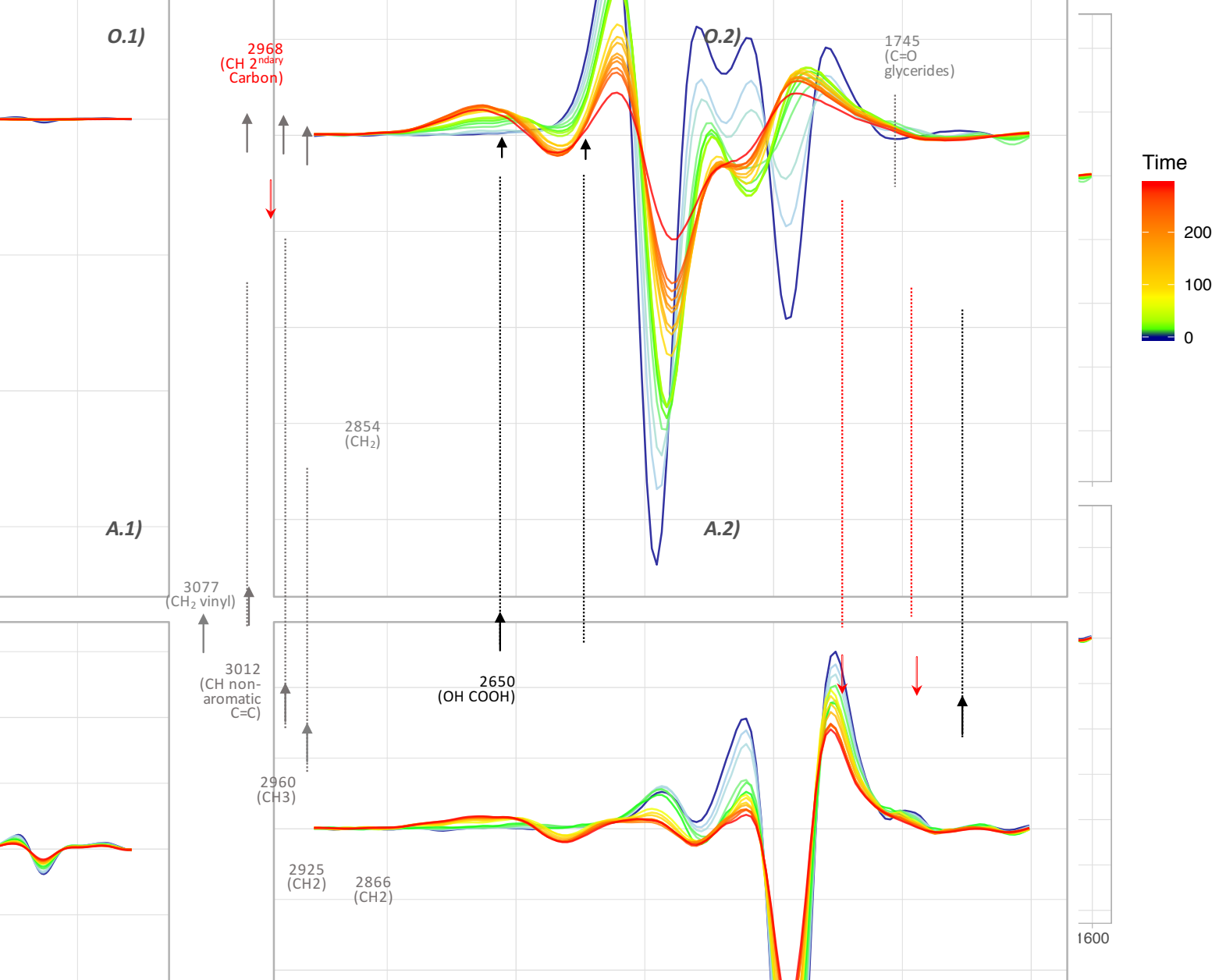

Figure 3 - Evolution of the second derivative infrared spectra of oil (O) and alcoholic (A) rosin varnishes between 3150 and 2450 $\mathrm{cm}^{-1}(1)$ and 2000 and $1550 \mathrm{~cm}^{-1}(2)$ during the irradiation in Suntest $\left(765 \mathrm{~W} \cdot \mathrm{m}^{-2}, 35^{\circ} \mathrm{C}\right)$.
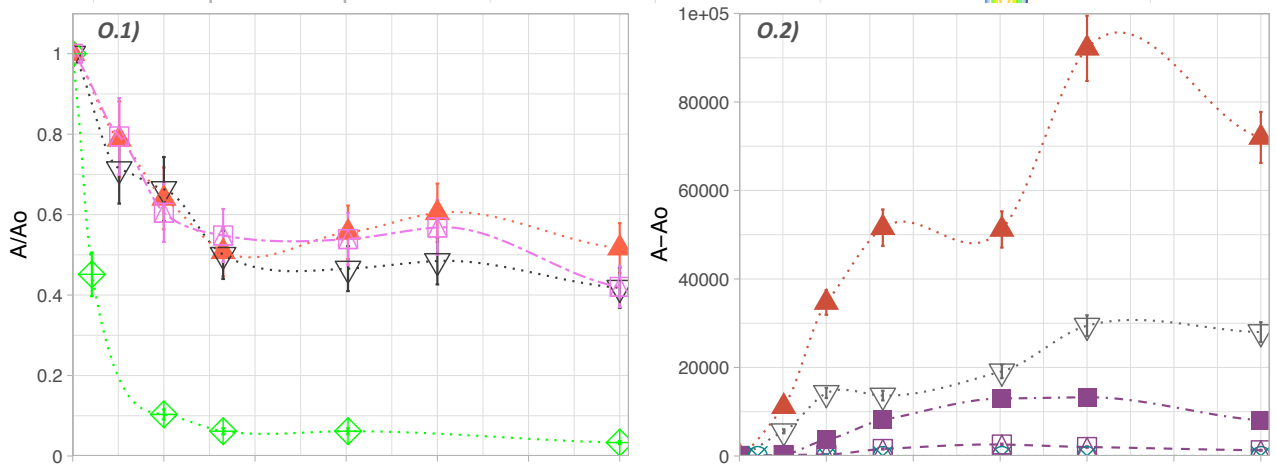

Compounds

$\nabla$ 18-nor-7-hydroxy-DHA

18-nor-abietic acid

18-nor-DHA

$\triangle$ 18-nor-isopimaradiene

18-nor-pimaradiene

$\square$ 18-nor-sandaracopimaradiene

$\nabla$ 7-hydroxy-DHA

$\gg$ 7-oxo-DHA

8. Abietic acid

$20000 \quad \begin{aligned} & \vdots \\ & \end{aligned} \quad \ldots$ A

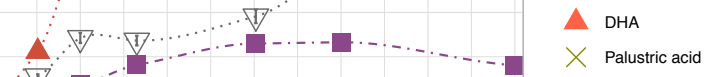
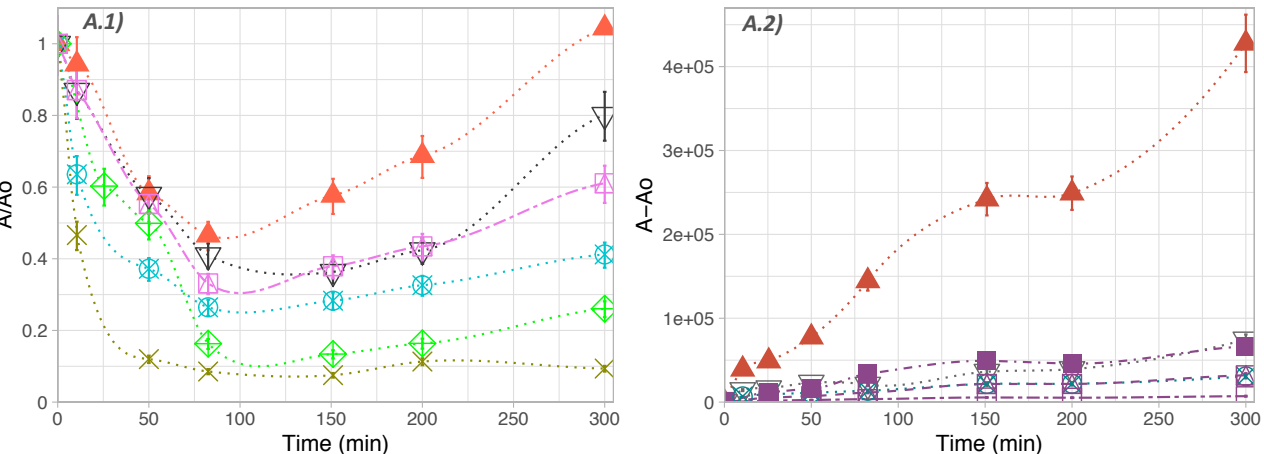

Figure 4 - Evolution of the relative concentrations of principal terpenes (1, on the left column) and their observed nor byproducts (2, on the right) in alcoholic $(\mathrm{A})$ and oil $(\mathrm{O})$ rosin varnishes during the irradiation in Suntest $\left(765 \mathrm{~W} \cdot \mathrm{m}^{-2}, 35^{\circ} \mathrm{C}\right)$. All quantifications were made by GC-MS after trimethylsilylation. Pimaranes (sandaracopimaric, pimaric, isopimaric acids) kinetics 
In alcoholic varnishes, the photoreactivities of the carboxylic groups of abietane and pimarane compounds were crucial in their degradation mechanism and led to the formation of dimers and polymers. Indeed, we could follow the infrared evolution of most characteristic bands of - $\mathrm{COOH}$ during the irradiation (cf Figure 3), with a special attention at the wavenumbers: (i) 2647 and $2535 \mathrm{~cm}^{-1}$ for their $\mathrm{O}-\mathrm{H}$ stretching, overtone and combination bands, ${ }^{[28,47]}$ (ii) $1695 \mathrm{~cm}^{-1}$ for their ketonic group, ${ }^{[45]}$ (iii) $1276 \mathrm{~cm}^{-1}$ for the stretching of the $\mathrm{OH}$ group. ${ }^{[45,48]}$ Such effect can be correlated to the huge loss of all free abietianes $(72 \%$ for palustric and abietic acid, 53\% for DHA) and pimaranes (52\% for pimaric acid, $64 \%$ and $69 \%$ for sandaracopimaric and isopimaric acids) detected by GC-MS during the phase 1 of the irradiation (cf Figure 4 ) with no major photoproducts detected. These two results clearly show that the main photochemical reactions in phase 1 are photochemical polymerization and cross-linking leading to the formation of high weight molecules.

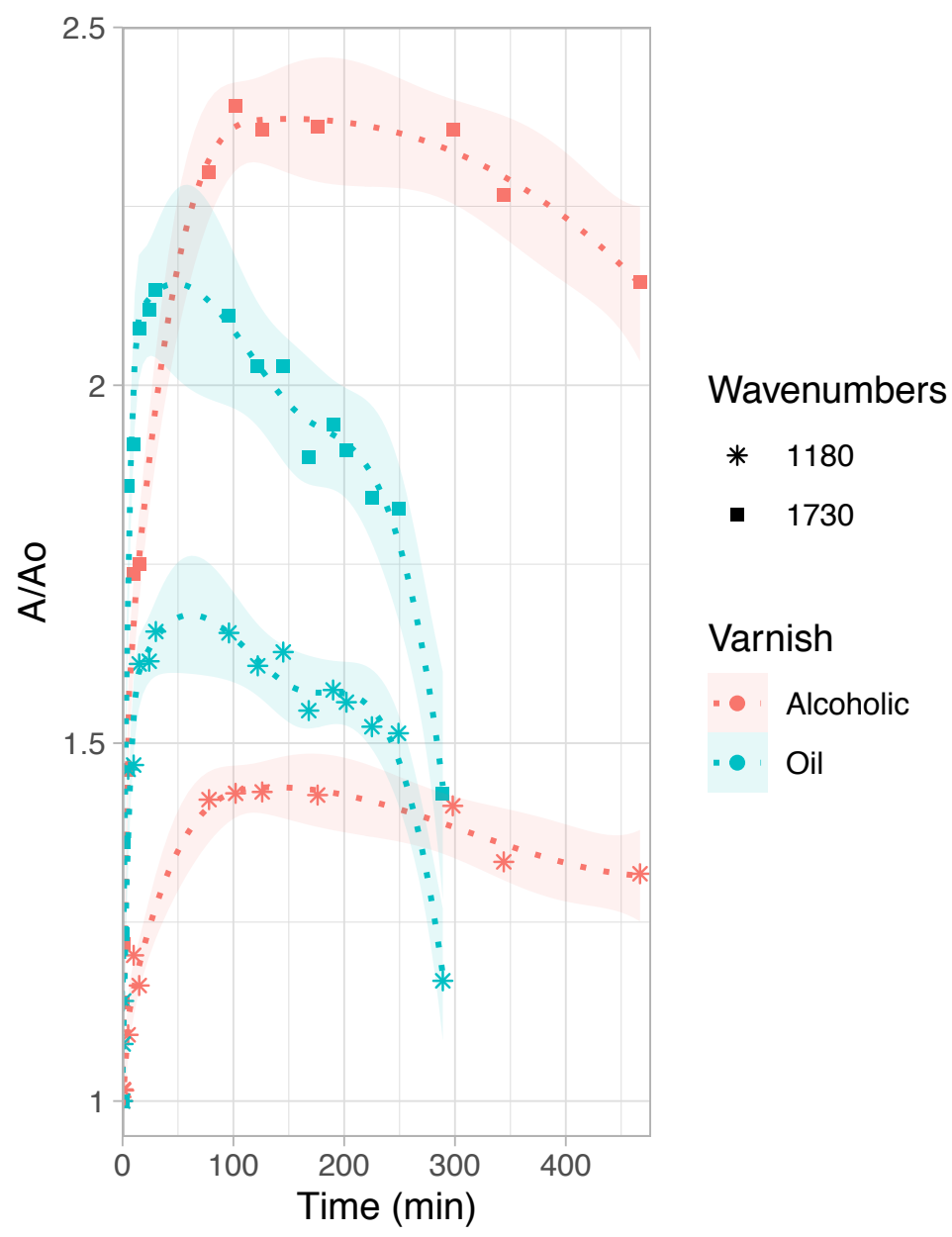

Figure 5 - Evolution the maximum of the infrared bands at 1730 and $1180 \mathrm{~cm}^{-1}$ during the irradiation of rosin varnishes in Suntest $\left(765 \mathrm{~W} \cdot \mathrm{m}^{-2}, 35^{\circ} \mathrm{C}\right)$.

During the photolysis, carboxylic acid undergoes esterification reactions as shown by the important formation of infrared bands of esters around $1730 \mathrm{~cm}^{-1},{ }^{[50,52-54]}$ and of peresters at $1780 \mathrm{~cm}^{-1},{ }^{[58,59,61,62]}$ (cf Figure 3 and Figure 5) during the first $100 \mathrm{~h}$ of irradiation. Moreover, the global increase of absorbance between 1250 and $950 \mathrm{~cm}^{-1}$ is notably attributed to the presence of esters and peresters $\mathrm{C}-\mathrm{O}$ bonds, ${ }^{[50,52]}$ as shown on Figure 6 . The band at $1780 \mathrm{~cm}^{-1}$ is usually attributed either to $\gamma$-lactones or peresters, ${ }^{[50,52,53]}$ nevertheless, in our conditions, no lactone was detected by GC-MS. Finally, these two absorption bands 
cannot be attributed to the formation of 7-oxo-DHA as the pure compound exhibits a carbonyl absorption around $1701 \mathrm{~cm}^{-1}$ (data not shown) and as free 7-oxo-DHA was not significantly formed in our conditions of irradiation (see Figure 4).

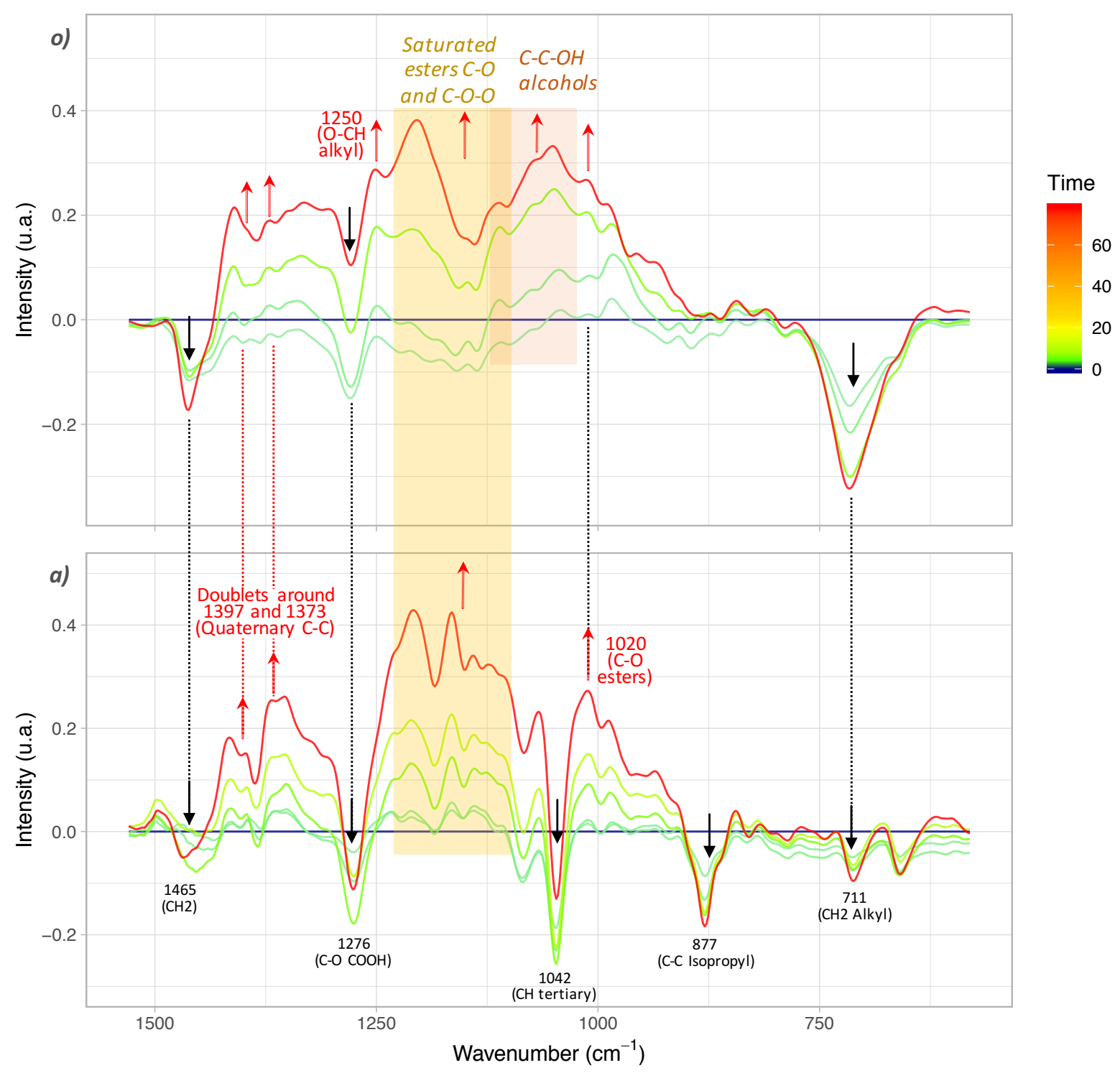

Figure 6 - Evolution of subtraction spectra (infrared spectra after various irradiation duration minus infrared spectra at $t 0$ ) of oil (O) and alcoholic (A) rosin varnishes between 1600 and $400 \mathrm{~cm}^{-1}$ during the irradiation in Suntest $\left(765 \mathrm{~W} \cdot \mathrm{m}^{-2}, 35^{\circ} \mathrm{C}\right)$.

Thus, abietane and pimarane can undergo photochemical condensation between carboxylic groups of pimaranes and abietanes and any alcohol group from other carboxylic acid or hydroxylated DHA. They also can react with peroxide radicals to form peresters. Such reactive species can be formed from any radical formed by autoxidation of natural resins, ${ }^{[2]}$ or photochemical process $\left(\mathrm{R}^{\bullet}+\mathrm{O}_{2} \rightarrow \mathrm{R}-\mathrm{O}-\mathrm{O}{ }^{\bullet}\right)$. The proposed mechanisms are given in Scheme 1. 


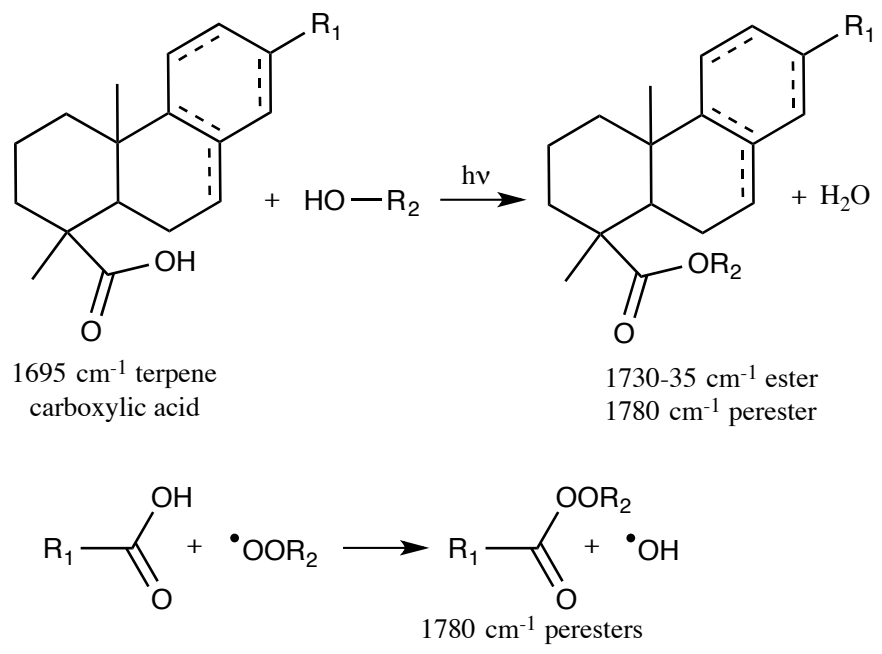

Scheme 1: Photochemical condensation of abietane and pimarane molecules.

The formation of hydroperoxides was noticed as evidenced by the formation of a broad band centered at $3425 \mathrm{~cm}^{-1}$ (cf Figure 7) that can be related to the process of formation of the esters in the varnish. Moreover, no significant increase of infrared absorption was noticed at $3470 \mathrm{~cm}^{-1}$, maximum of absorption of the broad band of alcohol function. Such result is in good accordance with other studies that prove the importance of the formation of peresters in the photochemical process. ${ }^{[45,57-59]}$

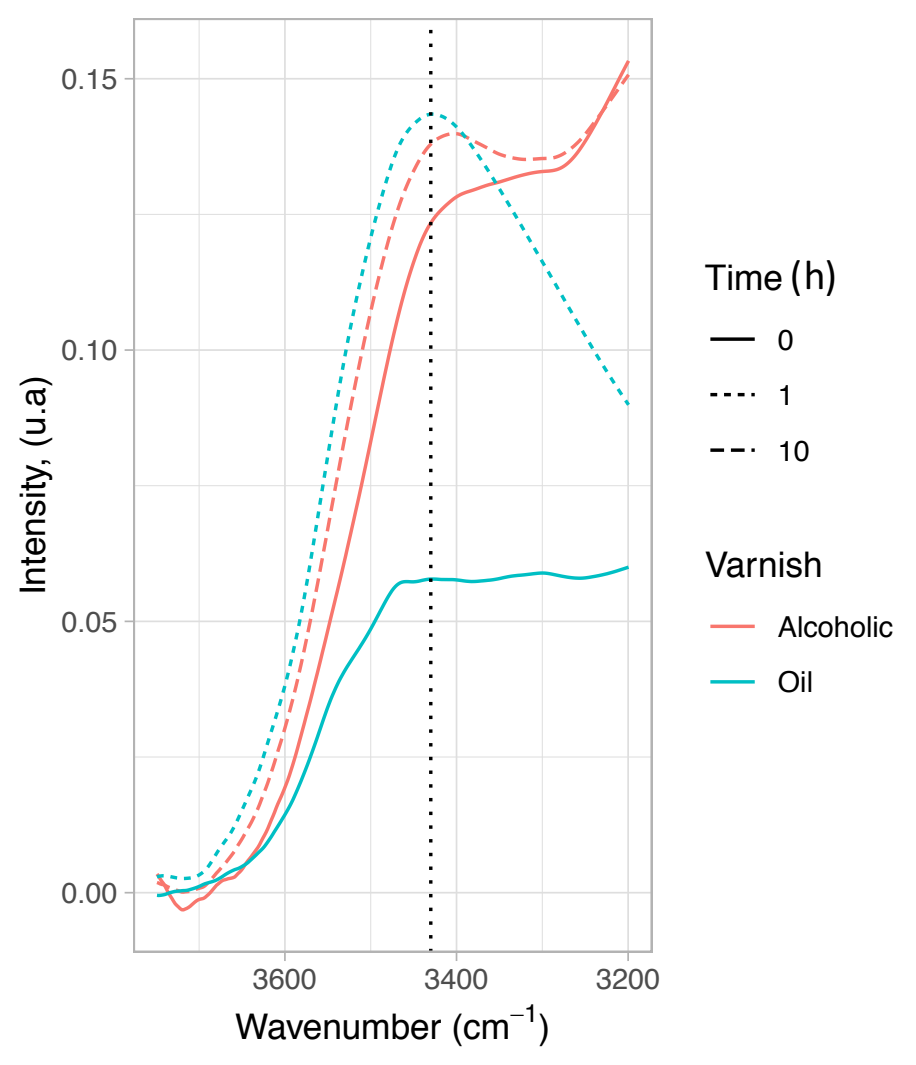

Figure 7 - Formation of the infrared band of hyperoxides (the $3425 \mathrm{~cm}^{-1}$ ) in alcoholic and oil rosin varnishes during first hours of irradiation. 
Moreover, the tertiary $\mathrm{CH}$ (2890 and $1047 \mathrm{~cm}^{-1}$ ) exhibit an important decrease as they are the most susceptible to form peroxide because of their lower energy of bond dissociation in regard of all other types of C-H bond, ${ }^{[57,58]}$ as proposed on Scheme 2. It is also noticeable that in position $\mathrm{C} 9$, the energy of $\mathrm{CH}$ bond is lowered by the presence of an unsaturation on the beta carbon $\mathrm{C} 8$. The high reactivity of all tertiary $\mathrm{CH}$ was detected by NMR during the irradiation of pure abietic acid in other publication. ${ }^{[45]}$ Besides, IR characteristic doublets of quaternary C-C (Figure 6), around 1397 and $1373 \mathrm{~cm}^{-1},{ }^{[53]}$ increased all over irradiation, most probably because of the reactivity of terpenes tertiary carbons C5, C9 and C15. Such peroxides easily induce the homolytic breakdown of the $\mathrm{O}-\mathrm{O}$ bonds in radicals. Moreover, such peroxides in tertiary carbon were detected during the irradiation of levopimaric, palustric and neoabietic acids in solution. ${ }^{[57,58,60]}$ Non aromatic secondary $\mathrm{CH}\left(3012 \mathrm{~cm}^{-1}\right)$ also suffer an important decrease, probably related to the peroxidation of the carbon 7, as shown in Scheme 2.

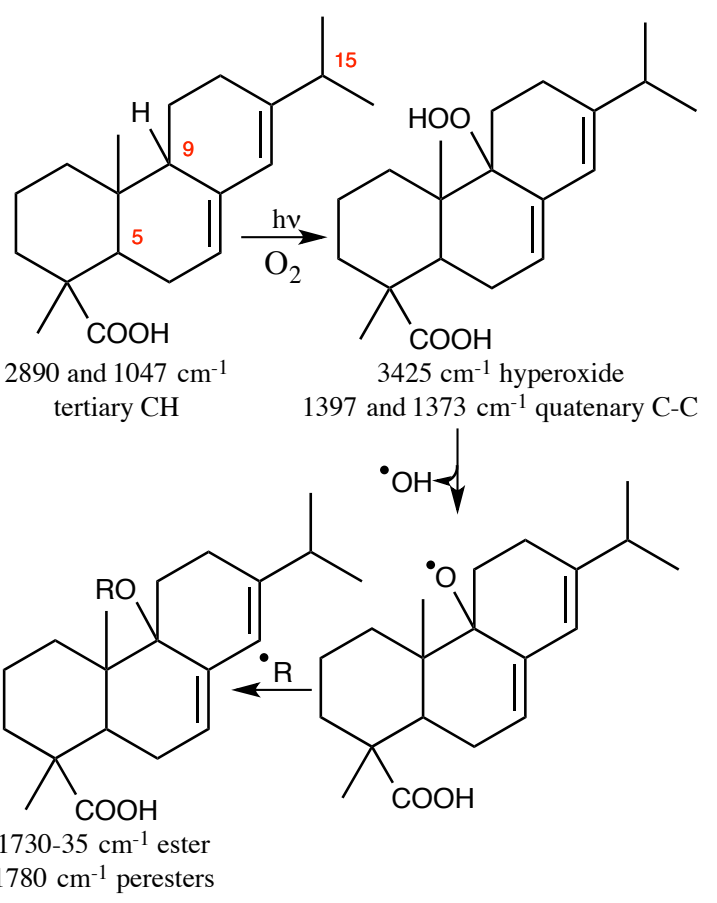

Scheme 2: Photoreactivity of abietane tertiary carbons.

Main reactions detected in phase 1 can involve different terpenes and lead to an increase of the molecular mass of the polymeric fraction. It fits nicely to previous results obtained by size exclusion chromatography showing the important formation of high molecular weight compounds during the photodegradation in rosin alcoholic varnishes. ${ }^{[38]}$ Other chemical pathways could lead to homolytic cleavage, intermolecular C-C or ether bonds formation or terpene oxidations.

After $100 \mathrm{~h}$ of irradiation (in phase 2) a slight decrease of esters and peresters bonds is observed (Figure 5) as the different abietane and pimarane started to be photochemically produced and detected by GC-MS (Figure 4). At the same time, there is a predominance of the formation of DHA and its 18-nor degradation products (Figure 4), possibly related to the slight augmentation of infrared bands around $1499(\mathrm{C}=\mathrm{C}$ stretching of aromatic rings) and $1612 \mathrm{~cm}^{-1}(\mathrm{C}=\mathrm{C}$ stretching of conjugated double bonds). It is worth noting that different hydroxylated DHA, with notably 7-hydroxy-DHA, are also formed in phase 2.

Thus, the polymeric fraction most probably begins to significantly absorb light and undergoes a secondary mechanism of photodegradation in phase 2 . Such mechanism highly depends on the chemical environment 
of the ester bond. We can propose a Norrish II reaction which notably leads to the formation of DHA with a dimer that contains abietic acid (cf Scheme 3).

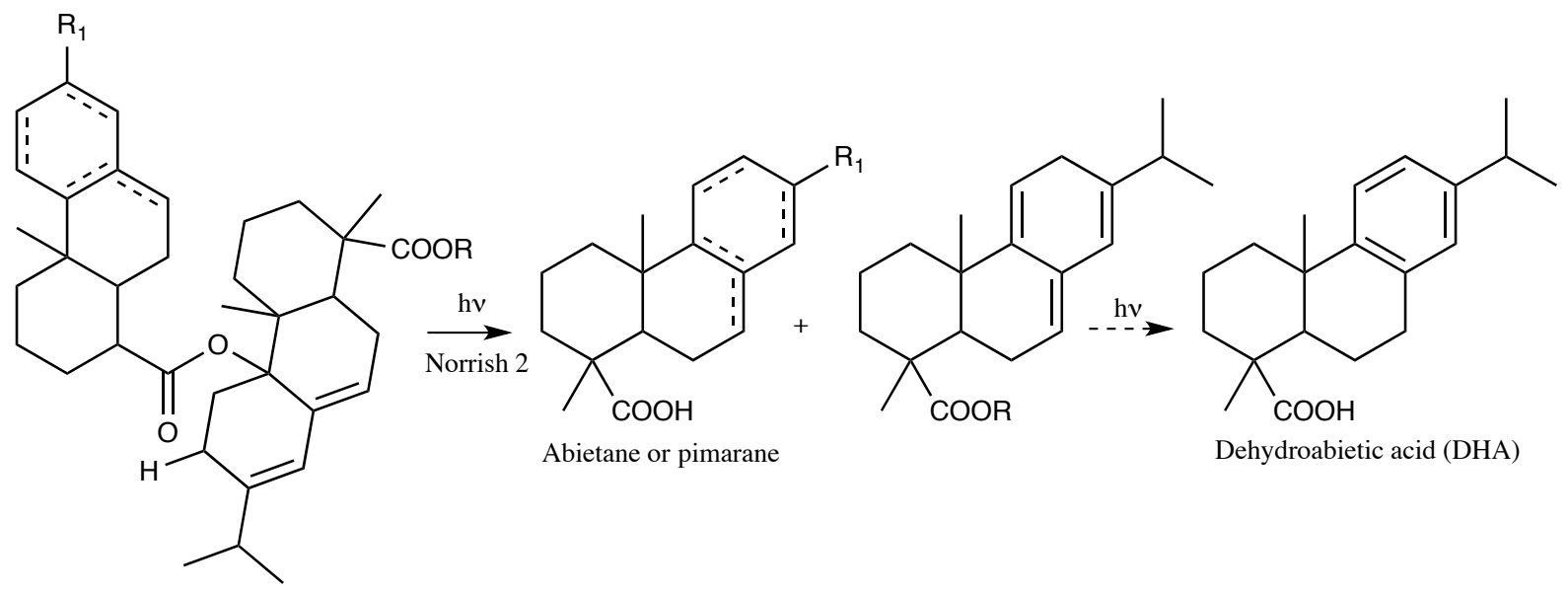

Scheme 3: Photodegradation of an abietic acid dimer via a Norrish II reaction.

The degradation of esters can also involve a Norrish I reaction followed by different radical oxidations and recombinations as proposed for a dimer terpene - DHA in Scheme 4. Such mechanism can notably explain the formation 7-hydroxy-acid and derivatives in phase 2 of the photolysis.

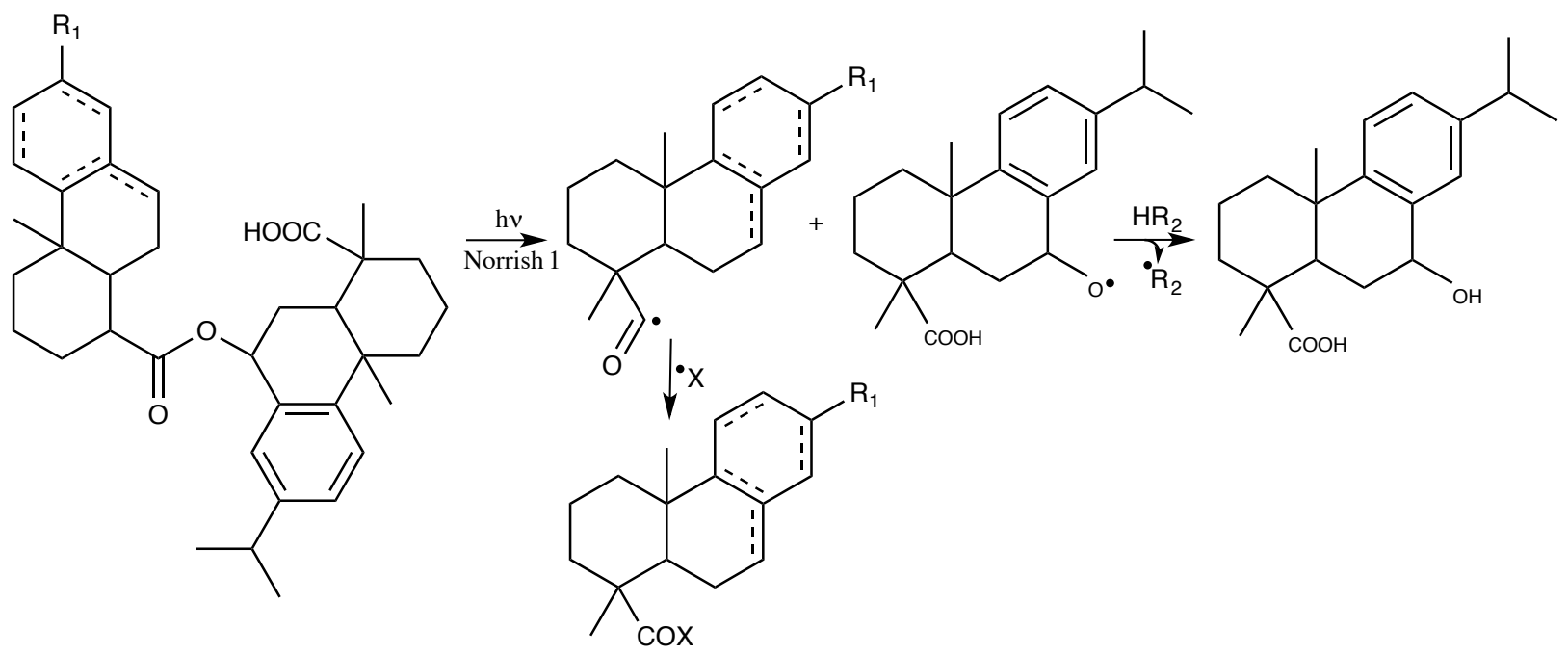

Scheme 4 : Photodegradation of ester dimers by Norrish I reaction

Norrish I and II reactions could explain the degradation of esters and the formation of carboxylic acids in phase 2. However, we cannot exclude the possibility of other homolytic cleavage, notably from peroxide bonds ( $\mathrm{R}-\mathrm{O}-\mathrm{O}-\mathrm{R} \rightarrow 2 \mathrm{R}-\mathrm{O}^{\bullet}$ ). The direct photooxidation of abietane and pimarane can also occur but is clearly not the main mechanism involved in the photochemistry of rosin alcoholic varnishes.

Low concentrations of 18-nor-abietane and 18-nor-pimarane compounds were also formed all along irradiation (cf Figure 4) and seem to be formed by direct photolysis leading to decarboxylation of free terpenes present in varnishes as proposed in Scheme 5: Photochemical decarboxylation of terpenes.

Such compounds could play a minor role in the decrease of $\mathrm{COOH}$ infrared bands and different abietane and pimarane concentrations. Nevertheless, their kinetics of formation suggests that they are generated 
from direct photolysis of the free abietane and primarane compounds. Such decarboxylation reactions were already reported in the direct photolysis of pure alcoholic solutions of abietic acid, ${ }^{[61]}$ and other terpenes. ${ }^{[62]}$<smiles></smiles>

Scheme 5: Photochemical decarboxylation of terpenes.

The evolution of second derivative of infrared spectra between 3150 and $2750 \mathrm{~cm}^{-1}$ pointed out an important decrease of $\mathrm{CH}_{2}\left(2925 \mathrm{~cm}^{-1}, 3077\right.$ and $2829 \mathrm{~cm}^{-1}$ for vinyl), $\mathrm{CH}_{3}\left(2958\right.$ and $\left.2867 \mathrm{~cm}^{-1}\right)$ and $\mathrm{CH}\left(3012 \mathrm{~cm}^{-1}\right.$ for non-aromatic, $2890 \mathrm{~cm}^{-1}$ for tertiary) bands. Such effect can be attributed to all chemical reactions taking place in varnishes involving carbons and possible molecule and fragment volatilizations. This explanation fits very well with the observed loss of mass of $8 \%$, in $800 \mathrm{~h}$ in good accordance with other study. ${ }^{[38]}$ The results also fit well the decrease of the concentrations of the main abietanes (abietic acid, DHA) of rosin in the phase 1 of the irradiation observed by GC-MS (Figure 4). The decrease of absorption of $\mathrm{CH}_{2}$ in vinyl bands at 3077 and $2829 \mathrm{~cm}^{-1}$ shows that the pimarane vinyl function exhibits a special reactivity, most probably by oxidation of the double bond principally leading to other cross-linking as no hydroxy-pimarane was detected by GC-MS. The decrease of absorption of $\mathrm{CH}_{2}$ in vinyl bands also comes from different intermolecular C-C cross-linking.

A part of $\mathrm{CH}_{2} / \mathrm{CH}_{3}$ bonds underwent a photooxidation in ether traduced by the increase of $\mathrm{H}-\mathrm{HCO}$ and $\mathrm{H}-$ $\mathrm{CH}_{2} \mathrm{O}$ bond characterized by an absorption band around $2844 \mathrm{~cm}^{-1},{ }^{[53]}$ as clearly noticed on Figure 3 . This $2844 \mathrm{~cm}^{-1}$ band is not present on the fresh resin spectrum and appears during the photochemical process. It could reflect the reactivity of some of the secondary carbons of abietane and pimarane (as the C7), ester, perester or ether bond formation or oxidations. 


\subsubsection{Photoreactivity of rosin oil varnishes}

During the fabrication (heating at $60-70{ }^{\circ} \mathrm{C}$ ) and drying of oil varnishes, the concentrations of different terpenes suffered important variations as shown in Figure 2. The concentrations of all chemicals strongly decreased with an almost complete disappearance of palustric, neoabietic and abietic acid. Moreover, the fatty acids, present in pure linseed oil, were very low in the extractable fraction of dry oil varnishes. Such effect was attributed to different cross-linking reactions between fatty acids, glycerides and terpenes of different types: esters, ethers, C-C and/or peroxy. ${ }^{[51,63,64]}$ Nevertheless, as we previously described, ${ }^{[43]}$ nonirradiated dry oil varnishes present infrared spectra similar to linseed oil, showing an important preservation of main oil chemical functions in the polymeric fraction. The dry oil varnishes presented an extractable fraction with chemical markers of rosin, saturated and unsaturated fatty acids (palmitic, stearic and oleic acids). Carboxylic function bands $\left(2647,2535\right.$ and $\left.1276 \mathrm{~cm}^{-1}\right)$ are very low after fabrication and drying of the varnish, most probably due to the efficiency of the polymerization process taking place during the heating of the mix of oil and rosin. ${ }^{[63]}$

During the irradiation, the carbonyl bands of terpenes, clearly identified at $1695 \mathrm{~cm}^{-1}$, and of glycerides $\left(1745 \mathrm{~cm}^{-1}\right)^{[52]}$ rapidly decreased in the first 100 hours of irradiation (phase 1) showing that those compounds rapidly polymerized. Also, all relative concentrations of abietane and pimarane rapidly decreased (around $50 \%$ of initial concentrations, Figure 4) without GC-MS detection of any major photoproducts. Alkyl IR bands at 1465 , and $725 \mathrm{~cm}^{-1}$ and the unsaturation on alkyl IR band at $975 \mathrm{~cm}^{-1}$ strongly decrease during the first $100 \mathrm{~h}$ of irradiation. Thus, glycerides suffered reaction involving the photodegradation of esters, unsaturation and alkyl chains. In this way, oleic acid concentration decreased while azelaic acid is formed in varnishes, most probably due to the photooxidation of the unsaturation as proposed in annex A. Moreover, we observed differences in the kinetics of this reaction with $\left(\lambda_{\text {exc }}>300 \mathrm{~nm}\right)$ or without $\left(\lambda_{\text {exc }}>290 \mathrm{~nm}\right)$ the indoor filter as shown in annexe A. When the indoor filter is used, azelaic acid is produced only during the first 100 hours of irradiation. Instead, when the filter is not present, the acid is formed all along the exposure time. On the other hand, the oleic acid shows a slight reformation after $100 \mathrm{~h}$. This effect could be related to the formation of fatty acids from glycerides during the irradiation with outdoor filter. Such interpretation is strengthened by the fact that the ester bonds of glycerides do not photochemically react at $\lambda>300 \mathrm{~nm}$ as other aliphatic polyesters. ${ }^{[65]}$

The apparition of peresters $\left(1780 \mathrm{~cm}^{-1}\right)$ and esters $\left(\mathrm{C}=\mathrm{O}\right.$ stretching $1735 \mathrm{~cm}^{-1}, \mathrm{C}-\mathrm{O}$ stretching around 1250 1150 and $\left.1020 \mathrm{~cm}^{-1}\right)^{[53,66]}$ increased during the phase 1 of irradiation. Such evolution indicates similar reactions to those described for alcoholic varnishes with MAG, DAG, fatty acids as possible reactive alcohols or carboxylic acids and classical photolysis of glycerides. ${ }^{[50]}$ Moreover, the increase of C-C-O alcohols (Figure 6, 1050-110 $\mathrm{cm}^{-1}$ ) ${ }^{[53]}$ and the amount of the broad band around $3465 \mathrm{~cm}^{-1}$ after $10 \mathrm{~h}$ of irradiation (data not shown) indicate the formation of alcohol in the medium, most probably linked to the photolysis of polymerized glycerides.

The IR spectra showed a rapid augmentation of the broad hydroperoxide alcohol band at $3430 \mathrm{~cm}^{-1}$ in the first hours of irradiation as shown in Figure 7. This result confirmed the great importance of hydroperoxides in oil varnishes photoreactivity, in good accordance with the literature. ${ }^{[50,67]}$ Such reaction involving tertiary carbons was shown to be effective even during the thermic degradations taking place at $60-70{ }^{\circ} \mathrm{C}$ in the preparation of the varnish. ${ }^{[68]}$

In phase two, oil varnishes show reactions similar to those observed in alcoholic varnishes, leading to the formation of esters and peresters (namely Norrish I and II reactions, with production of radicals and consequent recombination). As for alcoholic varnishes, 18-nor abietane and pimarane are formed all along 
the irradiation (cf Figure 4). The nor derivative of abietic acid, the 18-nor abietadiene, was not formed during the irradiation of oil varnishes.

The evolution of second derivative of infrared spectra between 3150 and $2750 \mathrm{~cm}^{-1}$ pointed out a global decrease of all $\mathrm{CH}$ infrared bands (Figure 3). Such effect could notably be attributed to the different reactions taking place in oil varnishes involving hydrogenated carbons. Moreover, the increase of nonaromatic-secondary carbon $\mathrm{CH}$ band at $2968 \mathrm{~cm}^{-1}$ could be related to the photodegradation of glycerides esters via a Norrish II reaction as proposed on Scheme 6 and already identified as an important photochemical pathway of poly(vinyl esters). ${ }^{[69]}$ Such mechanism fits well the formation of oleic acid observed during irradiation with outdoor filter.

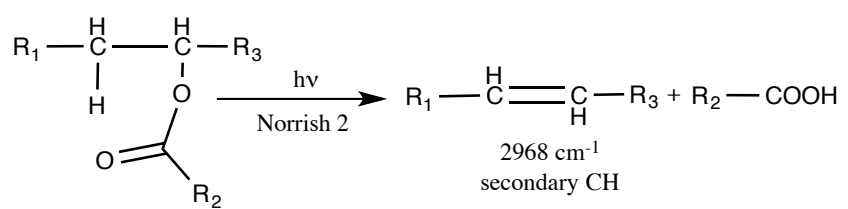

Scheme 6 : photodegradation of glycerides esters via a Norrish II reaction. 


\subsubsection{Considerations on the formation of highly oxidized abietanes}

Abietanes are known to undergo natural degradation in highly oxidized components (DHA, hydroxylatedDHA, 7-oxo-DHA, hydroxylated 7-oxo-DHA) most probably formed by radical autoxidation. ${ }^{[38,40,48,48,70]}$ According to our results, these previous reactions are not photochemical mechanisms of rosin varnishes. Moreover, we can strongly hypothesize that the polymerization process is mainly due to photochemical reactivity of the varnishes which promotes esterifications and peresterifications reactions and an increase of radical recombination.

Interestingly, some authors showed that the yellowing was more important if a painting was kept in dark after a light exposure. ${ }^{[73]}$ Such effect could be linked to an enhancement of radical oxidative processes by photochemically formed radical species.

It is also worth noticing that many important art manuals and treatises. ${ }^{[2-6,8,13,29,74-76]}$ recommend exposing varnishes to the sun during their drying. Such fabrication step actually promotes the polymerization and the formation of a high mass molecular network. 


\subsection{Photodegradation of sandarac varnishes}

The photodegradation of sandarac alcohol varnishes at $35^{\circ} \mathrm{C}$ and under simulated solar light was studied. As for rosin varnishes, all observed reactions were photochemically induced and followed by infrared spectrometry and GC-MS analyses of the extractable fraction. Indeed, no significant change in the chemical compositions of varnishes change was noticed after 1 month in the dark at ambient temperature $\left(20-25^{\circ} \mathrm{C}\right)$ or in an oven at $40^{\circ} \mathrm{C}$ (data not shown).

GC-MS chromatograms of all fresh sandarac varnishes were principally composed of pimaranes and labdanes, most particularly communic (trans and cis), sandaracopimaric, hydroxy-sandaracopimaric, 3 hydroxy-eperuic, agathic and pinifolic acids, sugiol and ferruginol. The GC-MS and infrared characterization of sandarac were already published by our team. ${ }^{[42,43]}$

First of all, dry sandarac varnishes most probably included a polymeric fraction as shown by the low concentrations of communic acids by GC-MS and the presence of non vinylic $-\mathrm{C}=\mathrm{C}$ - bonds detected by FT-IR spectroscopy. The other specificities of the fresh sandarac chemical composition were studied by GC-MS and FT-IR in previous published works. ${ }^{[42,43]}$

Sandarac varnishes showed a strong reactivity of the vinyl bonds with a strong decrease of all associated infrared absorption bands at $3077 \mathrm{~cm}^{-1}$ (vinyl CH$)^{[59]}, 3027 \mathrm{~cm}^{-1}$ (vinyl CH), $2987 \mathrm{~cm}^{-1}\left(=\mathrm{CH}_{2}\right.$ ), 2829 (vinyl $\mathrm{CH}_{2}$ ), 1643 (vinyl $\mathrm{C}=\mathrm{C}$ ), 1409 (vinyl $\mathrm{CH}_{2}$ ), $887\left(\right.$ vinyl $\left.\mathrm{CH}_{2}\right)$ as shown in Figure 8. Such result fits well the decrease of 50 to $80 \%$ in $300 \mathrm{~h}$ (GC-MS, cf Annex B) of communic (trans and cis), sandaracopimaric, hydroxy-sandaracopimaric, 3-hydroxy-eperuic, agathic and pinifolic acids, which contain such chemical function. It is worth noting that such vinyl function commonly reacts through hyperoxidation and polymerization.

The formation of trans and cis secondary alkenes, with characteristic bands at 1662, 1423, 1295 and 981 $\mathrm{cm}^{-1}$, could probably be related to the formation of high mass photoproducts of vinyl compounds. This result shows the importance of the vinyl functions in the photochemistry of sandarac resin in good accordance with the augmentation of high weight molecules previously described in various publications. ${ }^{[21,30]}$

These vinyl reactivities could be caused by the reaction of the double bond with oxygen, as already described in the photochemistry of vinyl compounds, ${ }^{[77-79]}$ leading to the formation of dialkyl ketones, ester or peroxy rings as proposed in Scheme 7. Such reactions lead to the augmentation of $\mathrm{CH}_{2}$ infrared bands at 2925, 2968 and $1460 \mathrm{~cm}^{-1}$ and diakyl ketone bands at $1714 \mathrm{~cm}^{-1},{ }^{[53]}$ and the decrease of $\mathrm{CH}$ acyclic alkane band at $1442 \mathrm{~cm}^{-1} \cdot[53]$

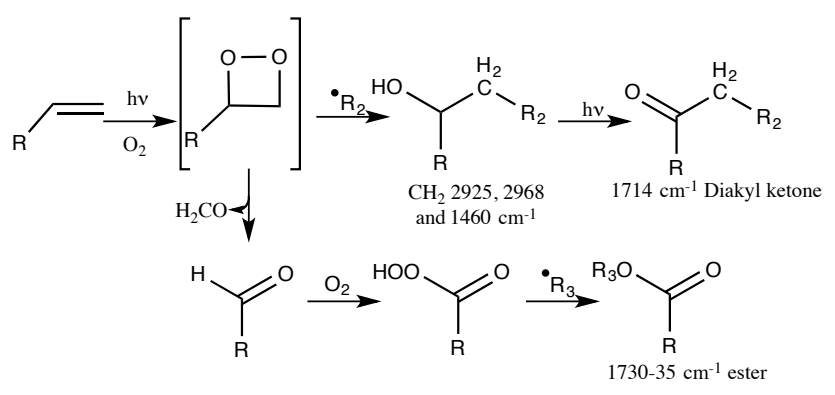

Scheme 7: Photodegradation pathways of vinyl terpene in sandarac varnishes. 
Moreover, photochemical esterification and peresterification similar to rosin varnishes could explain the similar behavior of sandarac terpenes regarding carboxylic acid, ester, perester, quaternary carbon, alcohol infrared bands (cf 2.1.1). Indeed, the majority of sandarac terpenes present similar carboxylic function on cycle A and similar position of tertiary carbons as rosin terpenes. One main difference for sandarac varnishes is the predominance of ester infrared band which could be related to the formation of an ester linked to vinyl reactivity. We also observe the formation of nor-pimarane and lower molecular weight labdanes by GC-MS, and the photo-isomerization of agathic acid in isoagathic acid (cf Annex C). For the phenols, the sugiol was completely degraded while the ferruginol stays stable during the whole irradiation.

Infrared bands characteristics of aldehydes at 2860 and $2726 \mathrm{~cm}^{-1}$ constantly decreased during the whole irradiation, probably caused by aldehyde oxidation in carboxylic acid as proposed by Kononenko et al. ${ }^{[32]}$

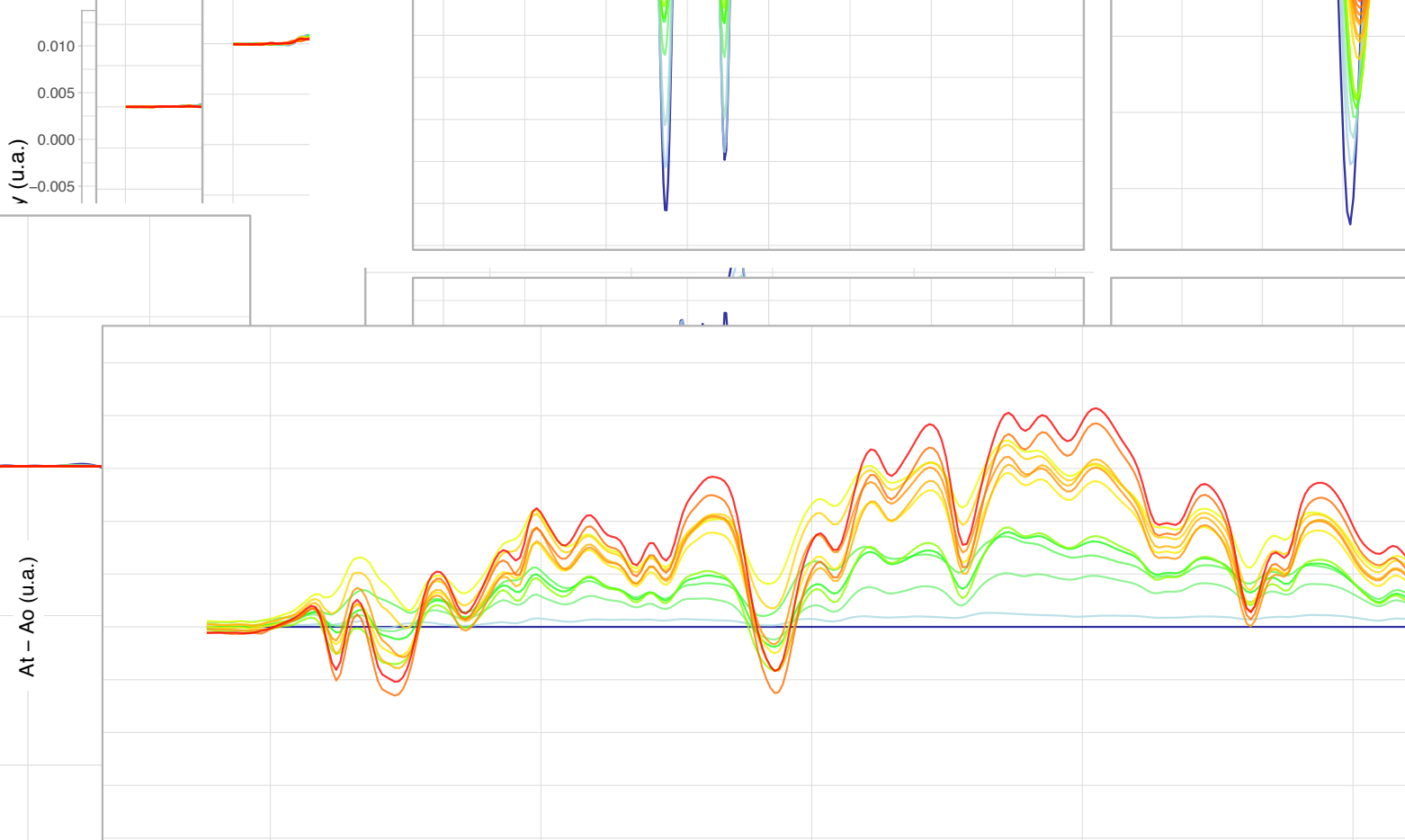

Figure 8 - (1) and (2) Evolution of the second derivative infrared spectra of sandarac varnishes between 3150 and $2450 \mathrm{~cm}^{-1}$ and 2000 and $1550 \mathrm{~cm}^{-1}$ during the irradiation in Suntest $\left(765 \mathrm{~W} \cdot \mathrm{m}^{-2}, 35^{\circ} \mathrm{C}\right)$. (3) Evolution of subtraction spectra (infrared spectra after various irradiation duration minus infrared spectra at t0) of sandarac alcoholic varnishes between 1600 and $400 \mathrm{~cm}^{-1} \mathrm{during}$ the irradiation in Suntest $\left(765 \mathrm{~W} \cdot \mathrm{m}^{-2}, 35^{\circ} \mathrm{C}\right)$. 


\section{Conclusion}

The photodegradation of sandarac and rosin (oil and alcoholic) at $35{ }^{\circ} \mathrm{C}$ and under simulated solar light allowed to identify the principal photochemical mechanisms. We showed that the carboxylic groups of abietane and pimarane compounds underwent the formation of esters and peresters dimers and polymers in the first $100 \mathrm{~h}$ of irradiation. The formation of hydroperoxyde was shown to take place preferentially on tertiary carbons. After $100 \mathrm{~h}$ of irradiation, the degradation of esters and peresters bonds, most probably by Norrish I and II reaction, lead to the production of free abietane and pimarane in the rosin varnishes. This second phase of photodegradation is probably related to the photochemical formation of crackling in the varnish. Low concentrations of 18-nor-abietane and 18-nor-pimarane compounds were also formed all along irradiation probably by direct photolysis of free terpenes. In oil varnishes, a strong effect of the formulation was shown, and glycerides and fatty acids were mainly responsible for the condensation of terpenes. We also identify many reactions that are specific to the oil photochemistry. In order to explain the differences with the natural degradation (formation of hydroxyl and keto abietane byproducts), we hypothesized that such oxidations products of abietanes could become important byproducts in absence of light, mainly driven by terpene autoxidation.

In the case of sandarac alcoholic varnishes, the vinyl bonds showed a strong reactivity associated with the formation of trans and cis secondary alkenes. This vinyl reactivity could be induced by the reaction of the double bond with oxygen leading to the formation of dialkyl ketones, ester or peroxy rings. Moreover, photochemical esterification and peresterification similar to rosin varnishes could explain the similar behavior of carboxylic acid of sandarac terpenes.

In this publication we provided a critic description of the photochemical mechanisms taking place in the varnishes. We showed that, firstly, the light helps the polymerization of the terpenes and, lastly, photodegrades the formed macromolecular network. The first step of this reaction can be related to the techniques of varnish application mentioned in many important art manuals and treatises that recommend exposing varnishes to the sun during their drying. Finally, the second step described is an important part of the problem of conservation of the varnish layers experienced by museum all over the world as it most probably leads to the crackling of the varnish. 


\section{Supporting Information Summary}

Supporting information include the experimental section, the annex A on the evolution of the relative concentrations of oleic and azelaic acids in oil rosin varnishes, the annex $\mathrm{B}$ on the evolution of the relative concentrations of the principal molecules composing sandarac and the annex $\mathrm{C}$ on the evolution of the relative concentrations of agathic and isoagathic acids compounds in sandarac spirit varnishes.

\section{$\underline{\text { Keywords }}$}

Diterpenic resin, Gas chromatography, IR spectroscopy, Photochemistry, Polymerization, Varnish 


\section{Bibliography}

[1] M. Favre-Felix, P. Pfister, Nuances 2015, 39, p 23-31.

[2] M. Théophile, C. de L'Escalopier, J.-M. Guichard, Theophili, presbyteri et monachi, Cte Charles De L'Escalopier, Paris, 1843, p. 314.

[3] J.-F. Watin, L'art Du Peintre, Doreur, Vernisseur, Grangé, Paris, 1774, p. 400.

[4] M. P. Merrifield, Medieval and Renaissance Treatises on the Arts of Painting: Original Texts with English Translations, Dover Publications Inc., London, 2012, p. 1286.

[5] P. F. Tingry, The Painter and Varnisher's Guide, J. Taylor, London, 1804, p. 614.

[6] A. M. Tripier-Deveaux, Traité théorique et pratique sur l'Art de faire les Vernis, G.J. Manget, Genève, 1845, p. 416.

[7] A. H. Sabin, The Industrial and Artistic Technology of Paint and Varnish, J. Wiley \& Sons, Incorporated, New York, 1917, p. 416.

[8] C. Cennini, G. Tambroni, A Treatise on Painting, Lumley, Paris, 1844, p. 308.

[9] H. Michetschläger, Ed., Violin Varnish: Notes and Articles from the Workshop of Koen Padding, Doratura, Sale, UK, 2015, p. 144.

[10] T. T. de Mayerne, Pictoria, sculptoria et quae subalternarum artium: 1620 le manuscrit, Audin, Lyon, 1977, p. 166.

[11] L. Mayer, Painting Conservation Catalog. Volume 1: Varnishes and Surface Coatings, W. Samet, Washington, 1998, p. 330.

[12] S. C. L. Eastlake, Methods and Materials of Painting of the Great Schools and Masters, Dover Publications Inc., London, 2001, p. 1024.

[13] R. I. Clark, A Few Notes on Varnishes and Fossil Resins, C. Letts, London, 1891, p. 69.

[14] Delormois, Le vernisseur parfait ou Manuel du vernisseur, C. A. Jombert, Paris, 1771, p. 250.

[15] J. Cameron, Oils and Varnishes, J. \& A. Churchill, London, 1886, p. 392.

[16] F. Buonanni, Traité de La Composition Des Vernis En Général, Nyon L'ainé, Paris, 1780, p. 205.

[17] Cité de la musique, Database VERNIX, https://vernix.philharmoniedeparis.fr/, 31 Oct. 2019.

[18] K. Nicolaus, Manuel de restauration des tableaux, Könemann, Köln, 1999, p. 425.

[19] E. R. de la Rie, Stud. Conserv. 1988, 33, 53-70.

[20] P. Dietemann, M. Kälin, S. Zumbühl, R. Knochenmuss, S. Wülfert, R. Zenobi, Anal. Chem. 2001, 73, 2087-2096.

[21] D. Scalarone, M. Lazzari, O. Chiantore, J. Anal. Appl. Pyrolysis 2003, 68-69, 115-136.

[22] I. Bonaduce, M. Odlyha, F. Di Girolamo, S. Lopez-Aparicio, T. Grøntoft, M. P. Colombini, Analyst 2013, 138, 487-500.

[23] J. Romero-Noguera, I. Martín-Sánchez, M. del M. López-Miras, J. M. Ramos-López, F. Bolívar- 
Galiano, Electron. J. Biotechnol. 2010, 13, 6-7.

[24] M. T. Doménech-Carbó, L. Osete-Cortina, J. de la Cruz Cañizares, F. Bolívar-Galiano, J. Romero-Noguera, M. A. Fernández-Vivas, I. Martín-Sánchez, Anal. Bioanal. Chem. 2006, 385, 12651280.

[25] M. Ménager, M. Sarakha, Environ. Sci. Technol. 2013, 47, 765-772.

[26] M. Ménager, X. Pan, P. Wong-Wah-Chung, M. Sarakha, J. Photochem. Photobiol. Chem. 2007, $192,41-48$.

[27] C. L. Mantell, C. H. Allen, K. M. Sprinkel, Ind. Eng. Chem. 1935, 27, 1369-1373.

[28] C. Azémard, $\mathrm{PhD}$ thesis, Avignon université (France), 2014.

[29] F. Perego, Dictionnaire des matériaux du peintre, Belin, Paris, 2005, p. 895.

[30] I. Kononenko, L. de Viguerie, S. Rochut, P. Walter, Environ. Sci. Pollut. Res. 2017, 24, 21602165 .

[31] C. Azémard, M. Ménager, C. Vieillescazes, Environ. Sci. Pollut. Res. 2017, 24, 27746-27754.

[32] I. Kononenko, PhD thesis, Université Pierre et Marie Curie (France), 2017.

[33] J. S. Mills, R. White, Organic Chemistry of Museum Objects. 2nde Ed., Oxford, 1994, p. 223.

[34] J. S. Mills, R. White, Stud. Conserv. 1977, 22, 12.

[35] J. H. Langenheim, Plant Resins: Chemistry, Evolution, Ecology, and Ethnobotany, Timber Press, Portland, 2003, p. 612.

[36] Y. Lu, Y. Hautevelle, R. Michels, Biogeosciences 2013, 10, 1943-1962.

[37] Y. Lu, PhD thesis, université de Lorraine (France), 2014.

[38] D. Scalarone, M. Lazzari, O. Chiantore, J. Anal. Appl. Pyrolysis 2002, 64, 345-361.

[39] J. Romero-Noguera, I. Martín-Sánchez, M. T. Doménech-Carbó, L. Osete-Cortina, M. M. LópezMiras, F. Bolívar-Galiano, Int. Biodeterior. Biodegrad. 2014, 90, 99-105.

[40] M. P. Colombini, F. Modugno, Eds., Organic Mass Spectrometry in Art and Archaeology, Wiley, Chichester, West Sussex, 2009, p. 493.

[41] N. Sugimoto, M. Kuroyanagi, T. Kato, K. Sato, A. Tada, T. Yamazaki, K. Tanamoto, Shokuhin Eiseigaku Zasshi J. Food Hyg. Soc. Jpn. 2006, 47, 76-79.

[42] C. Azémard, M. Ménager, C. Vieillescazes, Environ. Sci. Pollut. Res. 2017, 24, 1-9.

[43] C. Azémard, C. Vieillescazes, M. Ménager, Microchem. J. 2014, 112, 137-149.

[44] D. Ciofini, J. Striova, M. Camaiti, S. Siano, Polym. Degrad. Stab. 2016, 123, 47-61.

[45] S. Zumbühl, A. Brändle, A. Hochuli, N. C. Scherrer, W. Caseri, Anal. Chem. 2017, 89, 17421748 .

[46] J.-L. Liu, X.-M. Liu, W.-G. Li, L. Ma, F. Shen, Monatshefte Für Chem. - Chem. Mon. 2014, 145, 209-212. 
[47] V. Beltran, N. Salvadó, S. Butí, T. Pradell, Anal. Bioanal. Chem. 2016, 408, 4073-4082.

[48] V. Beltran, N. Salvadó, S. Butí, G. Cinque, T. Pradell, J. Nat. Prod. 2017, 80, 854-863.

[49] C. Azémard, M. Ménager, C. Vieillescazes, Anal. Bioanal. Chem. 2016, 408, 6599-6612.

[50] J. Mallégol, J.-L. Gardette, J. Lemaire, J. Am. Oil Chem. Soc. 2000, 77, 257-263.

[51] J. Mallégol, J.-L. Gardette, J. Lemaire, J. Am. Oil Chem. Soc. 1999, 76, 967-976.

[52] L. Bellamy, The Infrared Spectra of Complex Molecules, Vol. 1, Springer, London, 1975, p. 448.

[53] D. Lin-Vien, N. B. Colthup, W. G. Fateley, J. G. Grasselli, The Handbook of Infrared and Raman Characteristic Frequencies of Organic Molecules, Elsevier, London, 1991, p. 522.

[54] J.-P. Echard, L. Bertrand, A. von Bohlen, A.-S. Le Hô, C. Paris, L. Bellot-Gurlet, B. Soulier, A. Lattuati-Derieux, S. Thao, L. Robinet, B. Lavédrine, S. Vaiedelich, Angew. Chem. Int. Ed. 2010, 49, 197201.

[55] L. J. Bellamy, B. R. Connelly, A. R. Philpotts, R. L. Williams, Z. Für Elektrochem. Berichte Bunsenges. Für Phys. Chem. 1960, 64, 563-566.

[56] W. Dauben, W. Epstein, J. Org. Chem. 1959, 24, 1595-1596.

[57] R. N. Moore, R. V. Lawrence, J. Am. Chem. Soc. 1958, 80, 1438-1440.

[58] W. H. Schuller, R. V. Lawrence, J. Am. Chem. Soc. 1961, 83, 2563-2570.

[59] Y. Li, X. Liu, Q. Zhang, B. Wang, C. Yu, H. U. Rashid, Y. Xu, L. Ma, F. Lai, Molecules 2018, $23,2816$.

[60] W. H. Schuller, R. N. Moore, R. V. Lawrence, J. Am. Chem. Soc. 1960, 82, 1734-1738.

[61] J. C. Sircar, G. S. Fisher, J. Org. Chem. 1969, 34, 404-408.

[62] S. Pratap. Singh, Jacques. Kagan, J. Org. Chem. 1970, 35, 3839-3842.

[63] S. Tirat, I. Degano, J.-P. Echard, A. Lattuati-Derieux, A. Lluveras-Tenorio, A. Marie, S. Serfaty, J.-Y. Le Huerou, Microchem. J. 2016, 126, 200-213.

[64] W. J. Muizebelt, J. C. Hubert, R. A. M. Venderbosch, Prog. Org. Coat. 1994, 24, 263-279.

[65] J. F. McKellar, N. S. Allen, Photochemistry of Man-Made Polymers, Applied Science Publishers, London, 1979, p. 328.

[66] E. Yara-Varón, J. E. Joli, M. Balcells, M. Torres, R. Canela-Garayoa, RSC Adv. 2012, 2, 92309236.

[67] J. Mallégol, J.-L. Gardette, J. Lemaire, J. Am. Oil Chem. Soc. 2000, 77, 249-255.

[68] G. Teissedre, J. F. Pilichowski, S. Chmela, J. Lacoste, Polym. Degrad. Stab. 1996, 53, 207-215.

[69] K. J. Buchanan, W. J. McGill, Eur. Polym. J. 1980, 16, 319-324.

[70] R. F. Brown, G. B. Bachman, S. J. Miller, J. Am. Chem. Soc. 1943, 65, 623-626.

[71] A. Lattuati-Derieux, S. Gomes, S. Tirat, S. Thao-Heu, J.-P. Echard, E-Preserv. Sci. 2014, 11, 54 
63.

[72] K. J. Van Den Berg, J. J. Boon, I. Pastorova, L. F. Spetter, J. Mass Spectrom. 2000, 35, 512-533.

[73] P. Dietemann, C. Higgitt, M. Kälin, M. J. Edelmann, R. Knochenmuss, R. Zenobi, J. Cult. Herit. 2009, 10, 30-40.

[74] G. B. Armenini, On the True Precepts of the Art of Painting, B. Franklin, New York, 1977, p. 435 .

[75] R. Borghini, Riposo di Raffaello Borghini, Tomo II, Appresso Giorgio Marescotti, Fiorenza, 1584, p. 706.

[76] L. Da Vinci, J. S. Hawkins, A treatise on painting, Dover Publications Inc, London, 2014, p. 208.

[77] N. S. Allen, Ed., Photochemistry and Photophysics of Polymer Materials, J. Wiley, Hoboken, N.J, 2010, p. 689.

[78] H. Lachheb, C. Guillard, H. Lassoued, M. Haddaji, M. Rajah, A. Houas, J. Photochem. Photobiol. Chem. 2017, 346, 462-469.

[79] A. G. Griesbeck, M. Oelgemöller, F. Ghetti, CRC Handbook of Organic Photochemistry and Photobiology, Taylor \& Francis, Boca Raton (Fla.), 2012, p. 1694. 


\section{$\underline{\text { Table of Contents }}$}

The photodegradation of sandarac and rosin under simulated solar light undergo a two steps reaction. In a first step, main terpene molecules underwent esterification and perestererifications via the formation of hydroperoxides preferentially formed on tertiary carbons. In a second step, these esters and perester bonds underwent photoscissions by Norrish I and II reactions, leading to the production of free terpenes in the varnishes.

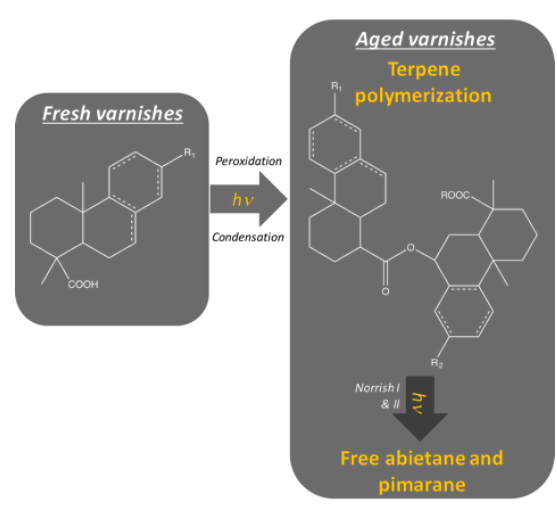

